\title{
Comparison of effects of two interval-training programmes on lactate and ventilatory thresholds
}

\author{
Jeff Burke, Robert Thayer PhD and Michael Belcamino \\ School of Physical Education and Department of Biology, Lakehead University, Thunder Bay, Ontario, Canada
}

\begin{abstract}
Twenty-one women subjects were matched in terms of their $\dot{V}_{2 \max }$ and assigned to one of two groups: (1) training at $30 \mathrm{~s}$; or (2) $2 \mathrm{~min}$ with a $1: 1$ work: relief ratio (1:1 WR) before participating in a 7 -week training programme which began at an intensity of $85 \% \dot{V}_{\mathrm{O}_{2} \max }$ and increased $5 \%$ every two weeks $\left(90 \%\right.$ and $\left.95 \% \dot{V}_{o_{2 m a x}}\right)$. The subjects trained to exhaustion four times per week. Maximal oxygen consumption $\left(\dot{V}_{\mathrm{O}_{2 \mathrm{max}}}\right)$, lactate threshold $\left(T_{1 \mathrm{ac}}\right)$ and ventilatory threshold ( $\left.T_{\text {vent }}\right)$ were determined before and after the training programme. After training, there were significant increases $(P<0.05)$ in $\dot{V} \mathrm{O}_{2 \max }(5 \%$ and $6 \%), T_{\text {lac }}$ (19.4\% and $22.4 \%)$, and $T_{\text {vent }}(19.5 \%$ and $18.5 \%)$. There were no significant group differences on any dependent measure but this research adds support to previous training studies in that a strong correlation $(P<0.05)$ between $T_{\text {lac }}$ and $T_{\text {vent }}$ is maintained from before to after the test. It was concluded that both formats of high intensity aerobic interval-training produce similar changes in $\dot{V}_{\mathbf{O}_{2 \max }}, T_{\text {lac }}$ and $T_{\text {vent }}$ and that these changes appear to be independent of the length of the work interval.
\end{abstract}

Keywords: Aerobic interval-training, lactate threshold ventilatory threshold

\section{Introduction}

The intensity and duration of exercise will determine the production and accumulation of lactate ${ }^{1,2}$. By altering the intensity of exercise and the work:rest ratio (WR), the contribution of anaerobic and aerobic metabolism to total energy needs may be manipulated $^{3}$. Skeletal muscle adapts to aerobic interval training (1:1 WR) with an increase in the capacity for aerobic metabolism and a decrease in lactate production ${ }^{4}$. But, as the intensity of interval work (1:1 WR) approaches and exceeds $100 \% \dot{V}_{O_{2 m a x}}$ the anaerobically generated acidosis becomes a major factor in contributing to muscular fatigue ${ }^{5}$.

The presence of lactate has been proposed to have a cause and effect relationship with $T_{\text {vent }}$ due to the carbon dioxide produced as a consequence of lactate buffering by the bicarbonate system ${ }^{6}$. Research evidence concerning this relationship is contradictory. Simon and colleagues ${ }^{7}$ have reported that $T_{\text {vent }}$ occurs before $T_{\text {lac }}$ whereas Walsh and Bannister ${ }^{8}$

Address for correspondence: Dr R. Thayer, School of Physical Education and Department of Biology, Lakehead University, Thunder Bay, Ontario P7B 5E1, Canada

(C) 1994 Butterworth-Heinemann Ltd 0306-3674/94/010018-04 described the opposite sequence of events. Our study employing two forms of high-intensity aerobic interval-training was therefore designed to clarify the proposed cause and effect relationship between $T_{\text {lac }}$ and $T_{\text {vent }}$. In addition, the metabolic responses of women subjects to two different interval training regimens were evaluated.

\section{Subjects and methods}

Informed consent was obtained from 21 women physical education students from Lakehead University to participate in the study. The group was pre-tested to establish baseline performance values for $\dot{V O}_{2 \max } T_{\text {lac }} T_{\text {vent }}$ and also to ascertain individual training work loads. Determination of $\dot{V}_{\mathrm{O}_{2} \max } T_{\text {lac }}$ and $T_{\text {vent }}$ were performed on the same day.

\section{Measurement of $\dot{V}_{\mathrm{O}_{2}}$}

The determination of $\dot{V}_{\mathrm{O}_{2 \max }}$ was performed in accordance with the procedures outlined by Hoppeler and colleagues ${ }^{9}$ and Tesch and colleagues ${ }^{10}$ on a Monark bicycle ergometer (Monark, Varberg, Sweden) at a cadence of 60 r.p.m. The subjects underwent a 4-min unloaded warm up at $0 \mathrm{~W}$. Thereafter, an increase in resistance of $30 \mathrm{~W}$ was applied to the ergometer. This load was maintained for $2 \mathrm{~min}$ and was subsequently increased by $30 \mathrm{~W}$ every 2 min until $\dot{V} \mathrm{O}_{2 \max }$ had been achieved ${ }^{\text {, }} 10$. Gas analysis was carried out using a pre-calibrated Beckman MMC Horizon II system (Beckman Instruments, Anaheim, California, USA). Heart rate was monitored employing a four lead electrocardiogram interfaced to the Beckman system. During the cycling test, blood was drawn into potassium oxalate/sodium fluoride vacuum tubes by an indwelling catheter from the antecubital vein. While exercising, blood samples were taken every $30 \mathrm{~s}$ until a heart rate of 190 beats $\mathrm{min}^{-1}$ was recorded. Blood was then drawn every $60 \mathrm{~s}$ until the cessation of exercise. At the conclusion of the test, blood was taken immediately and the plasma analysed using a Yellow Springs 23L Lactate analyser (YSI, Yellow Springs, Ohio, USA). $T_{\text {lac }}$ was determined using the double logarithm method of Beaver and colleagues ${ }^{11}$.

Ventilatory threshold was resolved using the $\dot{V}_{\mathrm{O}_{2 \max }}$ data obtained from the Beckman metabolic cart before and after testing. Calculation of $T_{\text {vent }}$ employed the $\dot{V}$-slope method $\left(\dot{V} \mathrm{CO}_{2} / \dot{V}_{2}\right)$ adapted from Wasserman and colleagues ${ }^{12}$. 
Table 1. Pre-training values* for subject characteristics-subjects were matched according to their $\dot{V}_{()_{2}}$ ax and placed into one of two training groups

\begin{tabular}{|c|c|c|c|c|}
\hline Group & $\begin{array}{c}\dot{V}()_{2 m x} \\
\left(m / k g{ }^{\prime} \min '\right)\end{array}$ & $\begin{array}{l}\text { Age } \\
\text { (years) }\end{array}$ & $\begin{array}{l}\text { Height } \\
\text { (cm) }\end{array}$ & $\begin{array}{c}\text { Weight } \\
(\mathrm{kg})\end{array}$ \\
\hline $\begin{array}{l}\text { Group } 1 \\
\qquad(n=10)\end{array}$ & $40.0(1.7)$ & $19.9(0.4)$ & $16.5(1.4)$ & $60.5(1.6)$ \\
\hline $\begin{array}{l}\text { Group } 2 \\
\quad(n=11)\end{array}$ & $39.9(1.5)$ & $20.8(0.7)$ & $16 . \overline{3}(1.3)$ & $64.8(3.8)$ \\
\hline
\end{tabular}

*Values are mean(s.e.)

\section{The training programme}

After testing for baseline values, subjects were matched in terms of their $\dot{V}_{\mathrm{O}_{2} \text { max }}$ and placed in one of two training groups to achieve homogeneity between groups. Subject characteristics for both groups are listed in Table 1. The groups consisted of: an interval-training group with a $30 \mathrm{~s}$ work: 30 s rest ratio (group 1) and an interval-training group with a 2-min work:2-min rest ratio (group 2). Participants attended four sessions per week for a period of 7 weeks (28 training sessions). During these periods subjects cycled to voluntary exhaustion on a Monark ergometer at a cadence of 60 r.p.m. against a predetermined resistance. During the first week (conditioning period) of the training programme subjects cycled at the workload which elicited $T_{\text {lac }}$. For the next 2 weeks, subjects exercised at a workload set to $85 \%$ $\dot{V}_{2 \max }$. During weeks 4 and 5 of the training programme, the work load was established at $90 \%$

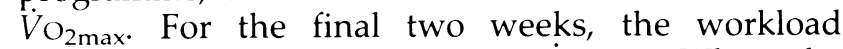
was further increased to $95 \% \quad \dot{V}_{\mathrm{O}_{2} \max }$. When the programme was completed, subjects were tested using the identical protocol to that used before the test.

\section{Statistical analysis}

The dependent measures, $\dot{V}_{\mathrm{O}_{2 \max }}, T_{\text {lac }}$ and $T_{\text {vent }}$ were analysed using a 2 (group) $\times 2$ (test) analysis of variance with repeated measures on the last factor. The Pearson product moment correlation test was used to determine the relationship between $T_{\text {lac }}$ and $T_{\text {vent }}$ values before and after testing. Differences for all dependent measures were considered significant at the $P<0.05$ level. The test analyses were carried out employing the SPSS/PC+V3 software package. (Statistical Package for the Social Sciences, SPSS, Chicago, Illinois, USA).

\section{Results}

Descriptive data of the physical and physiological characteristics of the subjects before training in both training groups are presented in Table 1. There were no significant differences between groups before the start of training for any variables.

After the 7-week training programme, both groups

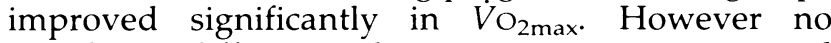
significant differences between groups were noted over time (Figure 1).

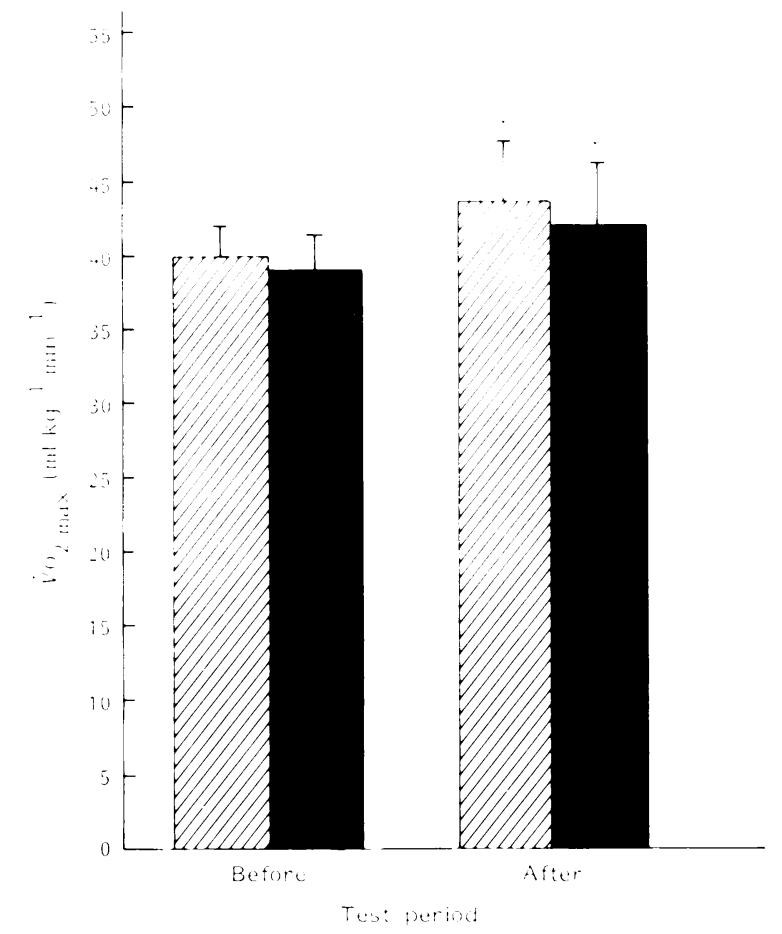

Figure 1. Mean(s.e.) changes in $\dot{V}_{O_{2} \max }$ for group 1 (training at 30-s work: 30 -s rest) and group 2 (training at 2-min work: 2-min rest) from before to after the test. No significant differences between groups were noted over time. * Within group significance for the two groups $P<0.05$; analysis of variance. $\square$, group $1 ; \square$, group 2

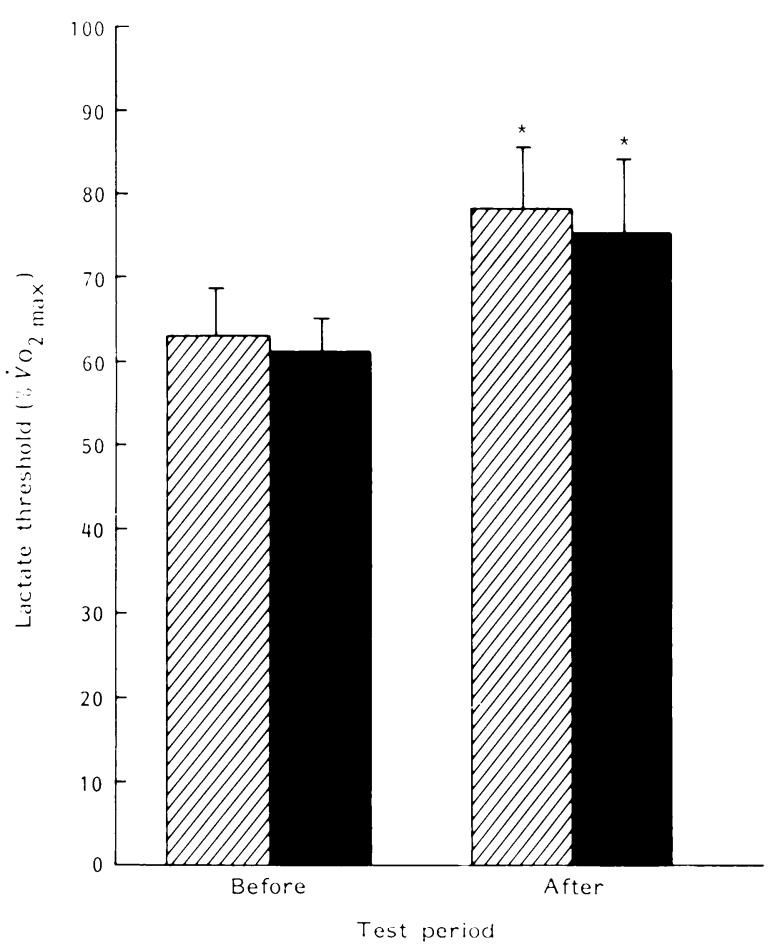

Figure 2. Mean (s.e.) changes in lactate threshold for group 1 (training at 30-s work: 30-s rest) and group 2 (training at 2-min work: 2-min rest) from before to after the test. No significant differences were noted between groups over time. ${ }^{*}$ Within group significance for both groups $P<0.05$; Pearson product moment correlation coefficient. $\square$, group $1 ; \square$, group 2 


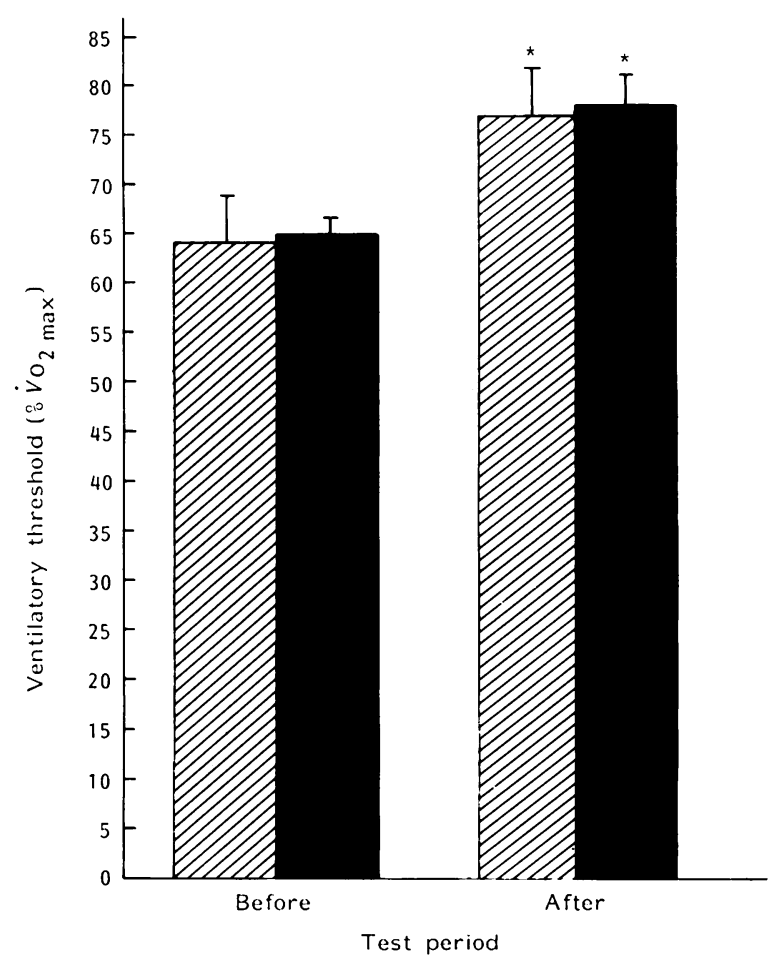

Figure 3. Mean(s.e.) changes in ventilatory threshold for group 1 (training at 30-s work: 30 -s rest) and group 2 (training at 2-min work: 2-min rest) from before to after the test. No significant differences were noted between groups over time. *Within group significance for both groups $P<0.05$; analysis of variance. $\square$, group 1 ; group 2

Table 2. Correlation between $T_{\mathrm{lac}}$ and $T_{\text {vent }}$ before and after the test

\begin{tabular}{lcc}
\hline Group & Condition & Correlation* \\
\hline Group 1 & Before & 0.83 \\
& After & 0.85 \\
Group 2 & Before & 0.94 \\
& After & 0.97 \\
\hline
\end{tabular}

*All values were significant at $P<0.05$; Pearson product moment correlation coefficient

Values for $T_{\text {lac }}$ (Figure 2) and $T_{\text {vent }}$ (Figure 3) after training are expressed as percentages of the posttraining $\dot{V}_{O_{2 \max }}$. Changes in $T_{\text {lac }}$ and $T_{\text {vent }}$ after training were statistically significant within groups, but not between groups (Figures 2 and 3). There were significant correlations between $T_{\text {lac }}$ and $T_{\text {vent }}$ before and after training for both groups 1 and 2 (Table 2).

\section{Discussion}

The increase in $\dot{V}_{\mathrm{O}_{2 \max }}$ demonstrated by both groups in the present investigation (Figure 1) is in agreement with other interval training studies which employed similar training intensities of $80-95 \% \dot{V O}_{2} \max ^{13,14}$. As well, research by MacDougall and Sale ${ }^{5}$ revealed that the greatest changes in aerobic capacity will occur when the work intensity exceeds $90 \% \dot{V}_{2} \max$.
Previous investigators have shown that the length of the work interval appears to affect the magnitude of the aerobic training response. Daniels and Scardi$\mathrm{na}^{15}$ suggested that exercise bouts lasting approximately $3-5 \mathrm{~min}$ are considered optimal for training the aerobic energy system. While Astrand and colleagues ${ }^{1}$ advised that a 2 -min work:2-min relief interval was considered more appropriate. As well, MacDougall and Sale ${ }^{5}$ reported that a work period of $30 \mathrm{~s}$ followed by a 30 -s rest interval would be inadequate in stressing aerobic capacity as compared with longer $2-3 \mathrm{~min}$ work periods. The longer 2-3 min work intervals would provide a greater degree of hypoxia. Furthermore, both the alactate and lactate energy systems would appear to be used to a greater extent with the $30 \mathrm{~s}$ as opposed to the 2 -min work interval ${ }^{5}$. However, the results of the present research contradict their findings as no significant differences in aerobic capacity were revealed between the 30-s and 2-min interval-training groups.

Previously, it has been shown that the greater intensity of exercise associated with aerobic intervaltraining yields more pronounced peripheral than central adaptations ${ }^{5}$. Increases in mitochondrial volume ${ }^{9,16}$, increased capillarization of muscle ${ }^{17}$, and an elevation in the concentration of the enzymes of both $\beta$ - and end-terminal oxidation ${ }^{18}$ provide the mechanism for a delay in lactate production after this form of training ${ }^{19}$ and may account for the observed $19.4 \%$ (group 1) and $22.4 \%$ (group 2) increase in $T_{\text {lac }}$ realized in this study. Formerly, it has been argued that extensive local adjustments in the oxidative potential of skeletal muscle can occur without a dramatic increase in $\dot{V}_{2 \max }{ }^{20}$. In our study there was a modest, but significant rise in $\dot{V}_{\mathrm{O}_{2} \max }$ of $6 \%$ (group 1) and 5\% (group 2) associated with the more dramatic elevation in both $T_{\text {lac }}$ and $T_{\text {vent }}$. The smaller volume and greater exercise intensity with this type of training may account for these differences.

In the present research, $T_{\text {vent }}$ and $\dot{V} \mathrm{O}_{2 \max }$ both increased significantly after the aerobic interval training programme (Figure 3 ) and this is in agreement with previous work ${ }^{21,22}$. However our data do not agree with the results of Acevedo and Goldfarb ${ }^{23}$ who revealed that $\dot{V}_{\mathrm{O}_{2 m a x}}$ and $T_{\text {vent }}$ did not change in spite of lower lactate levels at greater exercise intensities. Perhaps the conflicting findings may be due to the fact that the training programme employed by Acevedo and Goldfarb ${ }^{23}$ failed to provide the necessary training stimulus to promote a change in $\dot{V}_{\mathrm{O}_{2 \max }}$ in their well-conditioned subjects.

The hydrogen ion efflux from the muscle cell associated with lactate production is immediately buffered by the bicarbonate system ${ }^{19}$ and leads to the formation of carbon dioxide which is rapidly transferred to the lungs. Consequently, the carbon dioxide produced may be measured at the mouth and expressed in relation to $\dot{V}_{\mathrm{O}_{2}}$ as $\dot{V} \mathrm{CO}_{2} / \dot{V}_{\mathrm{O}_{2}}$. With the increase in the oxidative capacity of trained muscle, $T_{\text {lac }}$ is achieved at a greater percentage of $\dot{V}_{\mathrm{O}_{2 \max }}$. Below $T_{\text {lac }}$ lactate concentration for a given workload will be decreased after training and results in decreased bicarbonate buffering with the subsequent reduction in metabolically produced carbon dioxide. 
Our results revealed significant correlations between $T_{\text {lac }}$ and $T_{\text {vent }}$ both before and after the test (Table 2) and lends support to the cause and effect relationship between lactate formation and $T_{\text {vent }}$ previously described ${ }^{6,24,25}$. The strong correlation has been explained on the basis of the increased carbon dioxide produced as a result of lactate buffering by the bicarbonate system ${ }^{6,24,25}$. Furthermore Farrel and $\mathrm{Ivy}^{26}$ reasoned that lactate not only stimulates ventilation via increased carbon dioxide output, but also as a result of lactate being almost completely dissociated at physiological $\mathrm{pH}^{24}$. However this reported robust relationship between $T_{\text {lac }}$ and $T_{\text {vent }}$ has been questioned in the research literature ${ }^{23,26,27}$ and other mechanisms may therefore exist to produce the characteristic responses to incremental exercise. Further research is necessary to define the relationship between these two metabolic measures more clearly.

In summary, our results clearly demonstrate that changes in $V_{\mathrm{O}_{2 \max }} T_{\text {lac }}$ and $T_{\text {vent }}$ were not solely dependent on the duration of the work interval as both training groups experienced similar increases in the dependent measures. A finding unique to this study is the marked improvement in $T_{\text {lac }}$ and $T_{\text {vent }}$, concomitant with only modest changes in $\dot{V}_{\mathrm{O}_{2} \max }$. Perhaps, the greater peripheral than central adaptation associated with this type of training ${ }^{28}$ may account for our findings. Finally, this investigation, in reporting a strong correlation between $T_{\text {lac }}$ and $T_{\text {vent }}$ before and after testing, is in agreement with previous studies which employed a similar form of training.

\section{Acknowledgements}

The authors would like to acknowledge the assistance of $\mathrm{Mr}$ Carlos Zerpa for his technical support. This research was supported in part by funds to Lakehead University from NSERC to Dr R. Thayer.

\section{References}

1 Astrand I, Astrand PO, Christensen EH, Hedman R. Intermittent muscular work. Acta Physiol Scand 1960; 48: 448-53.

2 Olsen R, Berg K, Latin R, Blanke D. Comparison of two intense interval training programs on maximum oxygen uptake and running performance. $J$ Sports Med Phys Fitness 1988; 28: 158-64.

3 Fox EL, Robinson S, Wiegman DL. Metabolic energy sources during continuous and interval running. J Appl Physiol 1969; 27: 174-8.

4 Jansson E, Dudley GA, Norman B, Tesch PA. Relationship of recovery from intense exercise to the oxidative potential of skeletal muscle. Acta Physiol Scand 1990; 139: 147-52

5 MacDougall D, Sale D. Continuous vs. interval training: a review for the athlete and coach. Can J Appl Sport Sci 1981; 6 : 93-7.
6 Yoshida T, Udo M, Chida M, Makiguchi K, Ichioka M, Muraoka I. Arterial blood gases, acid base balance, and lactate and gas exchange variables during hypoxic exercise. Int J Sports Med 1989; 10: 279-85.

7 Simon J, Young JL, Blood DK, Segal KR, Case RB, Gutin B. Plasma lactate and ventilation thresholds in trained and untrained cyclists. J Appl Physiol 1986; 60: 777-81.

8 Walsh ML, Bannister EW. Possible mechanisms of the anaerobic threshold: a review. Sports Med 1988; 5: 269-302.

9 Hoppeler $\mathrm{H}$, Howald $\mathrm{H}$, Conley $\mathrm{K}$, Lindstedt SL et al. Endurance training in humans: aerobic capacity and structure of skeletal muscle. J Appl Physiol 1985; 59: 320-27.

10 Tesch PA, Sharp DS, Daniels WL. Influence of fiber type composition and capillary density on onset of blood lactate accumulation. Int J Sports Med 1981; 4: 252-5.

11 Beaver WL, Wasserman K, Whipp, BJ. Improved detection of lactate threshold during exercise using a log-log transformation. I Appl Physiol 1985; 59: 1936-40.

12 Wasserman K, Hansen JE, Sue DY, Whipp BJ. Principles of exercise testing and interpretation. Philadelphia, USA: Lea and Febiger, 1987: 42.

13 Dolgener FA, Brooks WB. The effects of interval and continuous training on $\dot{\mathrm{V}}_{2 \max }$ and performance on the mile run. I Sports Med Phys Fitness 1978; 18: 345-52.

14 Thomas TR, Adeniran SSB, Etheridge GL. Effects of different running programs on $\dot{V}_{\mathrm{O}_{2 \max }}$ percent fat, and plasma lipid. Can J Appl Sport Sci 1984; 9: 55-62.

15 Daniels J, Scardina N. Interval training and performance. Sports Med 1984; 1: 327-34.

16 Brooks GA. Anaerobic threshold: review of the concept and directions for future research. Med Sci Sports Exerc 1985; 17: 22-31.

17 McLellan TM, Jacobs I. Active recovery, endurance training and the calculation of the individual anaerobic threshold. Med Sci Sports Exerc 1989; 21: 586-92.

18 Saltin B, Nazar K, Costill DL, Stein E et al. The nature of the training responses; peripheral and central adaptations to one-legged exercise. Acta Physiol Scand 1976; 96: 289-305.

19 Wasserman K, Beaver WL, Whipp BJ. Mechanisms and patterns of blood lactate increase during exercise in man. Med Sci Sports Exerc 1986; 18: 344-52.

20 Gollnick PD, Saltin B. Significance of skeletal muscle oxidative enzyme enhancement with endurance training. Clin Physiol 1982; 2: 1-12.

21 Morton HR, Gass GC. A systems model approach to the ventilatory threshold. Eur J Appl Physiol 1987; 56: 367-73.

22 Poole DC, Gaesser GA. Response to ventilatory and lactate thresholds to continuous and interval training. J Appl Physiol 1985; 58: 1115-21.

23 Acevedo EO, Goldfarb AH. Increased training intensity effects on plasma lactate, ventilatory threshold and endurance. Med Sci Sports Exerc 1989; 21: 563-8.

24 Casaburi R, Storer TW, Wasserman K. Mediation of reduced ventilatory response of exercise after endurance training. I Appl Physiol 1987; 1533-8.

25 Langill RH, Rhodes EC. Comparison of the lactate and ventilatory responses during a progressive intensity test. Australian J Sci Med Sport 1992; 24: 16-18.

26 Farrel SW, Ivy JL. Lactate acidosis and the increase in $\dot{V} E / \dot{V}_{\mathrm{O}_{2}}$ during incremental exercise. J Appl Physiol 1987; 62: 1551-5.

27 Hughes EF, Turner SC, Brooks GA. Effects of glycogen depletion and pedalling speed on 'anaerobic threshold'. J Appl Physiol 1982; 52: 1598-607.

28 Holloszy JO, Coyle EF. Adaptations of skeletal muscle to endurance exercise and their metabolic consequences. J Appl Physiol 1984; 56: 831-8. 